\title{
Clinical factors affecting the outcome of arthocentesis
}

\author{
Syed Wakeel Andrabi, Altaf H. Malik, Ajaz A. Shah \\ Department of Oral and Maxillofacial Surgery, Government Dental College, Srinagar, India
}

\begin{abstract}
J Korean Assoc Oral Maxillofac Surg 2019;45:9-14)
Objectives: This study aimed to evaluate the effect of clinical factors on the outcome of arthrocentesis in the treatment of temporomandibular joint (TMJ) internal derangement.

Materials and Methods: Fifty patients with TMJ internal derangement underwent arthrocentesis using ringer's lactate. The present study evaluated the contribution of the clinical variables of age, time since onset, visual analogue scale (VAS) pain level, and range of motion (ROM) on the outcomes of TMJ arthrocentesis: age ( $\leq 25$ years, $>25$ and $\leq 40$ years, $>40$ and $\leq 60$ years), VAS pain level $(\leq 5,>5$ and $\leq 7,>7$ and $\leq 10)$, and $\operatorname{ROM}(<25$ and $\geq 25$ $\mathrm{mm}$ ). Odds ratios (ORs) were used to describe the proportional benefit of each variable the on successful outcome of arthrocentesis. For the OR to be clinically relevant or even clinically noticeable, we assumed that the OR would need to be larger than 2 .

Results: Mean preoperative pain score was $6.49 \pm 1.560$ and at 6 months postoperative was $0.46 \pm 1.147$ with an average decrease of pain score 6 $(P<0.001)$. The mean preoperactive maximum mouth opening was $26.14 \pm 4.969 \mathrm{~mm}$ and mean maximum mouth opening at 6 -month inerval was $38.92 \pm 3.392 \mathrm{~mm}$. The mean increase in the mouth opening was a mean difference of $12.78 \mathrm{~mm}(P<0.001)$. Logistic regression showed that the maximum benefit occurred in patients aged $<25$ years (OR, 12.01; $P=0.012$ ), a VAS pain level of $>7(\mathrm{OR}, 11.25 ; P=0.039)$, and a maximum vertical opening of $<25 \mathrm{~mm}(\mathrm{OR}, 7.70 ; P=0.038)$.

Conclusion: Lavage of the superior joint space with ringer's lactate resulted in significant reduction in pain and improvement in mouth opening. Patients with a greater inflammatory component and younger patients benefitted more from arthrocentesis. Evaluation of these clinical variables helped in predictive modelling, which may provide clinicians with the opportunity to identify "at-benefit" patients early and initiate specific treatment.
\end{abstract}

Key words: Temporomandibular joint, Internal derangement, Arthrocentesis

[paper submitted 2017. 12. 27 / revised 1st 2018. 1. 23, 2nd 2018. 2. 12, 3rd 2018. 2. 22 / accepted 2018. 3. 5]

\section{Introduction}

Internal derangement of the temporomandibular joint (TMJ) is characterized by displacement of the intra-articular disc, resulting in clicking and popping sounds. However, displacement of the articular disc does not always cause a mechanical obstruction. These conditions may be painless or may be associated with pain, especially during function. The most common causes are trauma, which results in an immediate displacement of the disc, or chronic parafunction, which results

\footnotetext{
Altaf H. Malik

Department of Oral and Maxillofacial Surgery, Government Dental College, Srinagar 190010, India

TEL: +91-1942504701 FAX: +91-9419031831

E-mail:drmalikaltaf@gmail.com

ORCID: https://orcid.org/0000-0002-7420-0035

(c) This is an open-access article distributed under the terms of the Creative Commons Attribution Non-Commercial License (http://creativecommons.org/ licenses/by-nc/4.0/), which permits unrestricted non-commercial use, distribution, and reproduction in any medium, provided the original work is properly cited.

Copyright (C) 2019 The Korean Association of Oral and Maxillofacial Surgeons. All rights reserved.
}

in degenerative changes in the articular surfaces, increased friction, and gradual disc displacement.

TMJ internal derangement has always been a therapeutic challenge for maxillofacial surgeons. Up to $25 \%$ of the entire population has internal TMJ derangement and are usually treated with nonsurgical methods including medications, physiotherapy, and occlusal splints in the initial period. When these methods are unsuccessful, TMJ is often managed by surgical methods. The mainstay of surgical treatment is based on changing the morphology or position of the disc or removal of the disc with or without replacement. There are variable reports of success with open surgical methodologies; these are associated with surgical risks and potential long term sequelae $^{1}$.

New insights into the joint pathology of TMJ internal derangement were provided by observations made during TMJ arthroscopic lysis and lavage and outcomes after such treatment. The physical action of lysis and lavage in the superior joint space, rather than disc repositioning, is believed to be responsible for the success of arthroscopic surgery ${ }^{2,3}$. This has 
led to the use of TMJ arthrocentesis as a relatively less invasive alternative to reduce the inflammation in the superior joint space and restore normal range of motion (ROM) ${ }^{2}$. This study aimed to discuss the role of arthrocentesis in the treatment of TMJ internal derangement and evaluate the clinical variables affecting arthrocentesis outcomes.

\section{Materials and Methods}

This study was approved by the chairman of Department of Oral and Maxillofacial Surgery, Government Dental College, Srinagar, India (approval no. 2012-omfs-GDC Srinagar-1), and the written informed consents were obtained from all patients.

This prospective clinical study was conducted on fifty patients with TMJ internal derangement at our institution from June 2012 to January 2015. Criteria patient for selection was based on history and clinical findings characteristic of internal derangement ${ }^{4}$. All patients were initially treated with nonsurgical methods and failed to respond to these conservative treatments. A screening TMJ view radiograph was taken in all cases to rule out gross degenerative joint diseases. Patients with degenerative joint diseases causing TMJ dysfunction including osteoarthritis, rheumatoid arthritis, and gout were excluded. Patients with previous surgical intervention for TMJ were also excluded. A total of 50 patients with TMJ internal derangement with failed conservative management were included in this study. Of the 50 patients, 20 had nonreducing disc displacement, 16 had reducing disc displacement, and

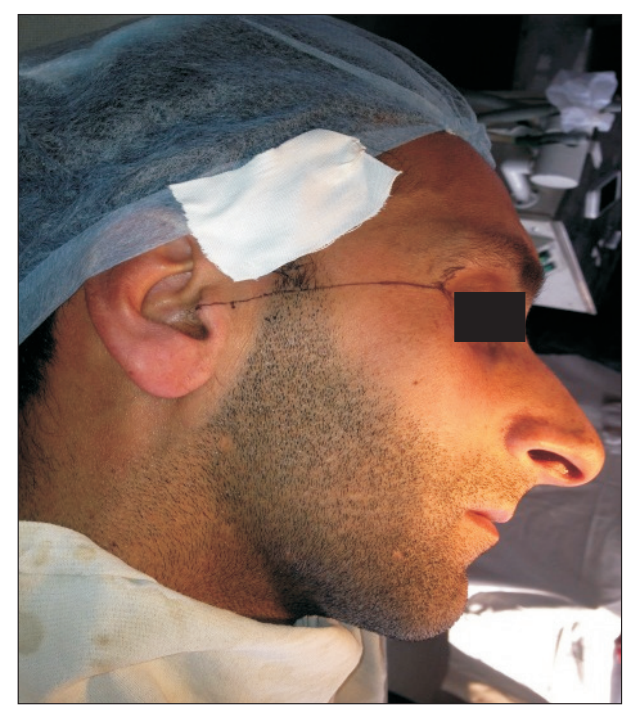

Fig. 1. Landmarks for arthrocentesis.

Syed Wakeel Andrabi et al: Clinical factors affecting the outcome of arthocentesis. $J$ Korean Assoc Oral Maxillofac Surg 2019
14 had reducing disc displacement with intermittent locking; all were treated with TMJ arthrocentesis. Arthrocentesis was performed in the superior joint space under aseptic precautions. Patients were seated at a $45^{\circ}$ angle; the points of needle insertion were marked on the skin according to the method suggested by McCain and Hossameldin ${ }^{5}$. A Holmlund-Hellsing line was drawn from the middle of the tragus to the outer canthus. Entry points were marked along this canthotragal line.(Fig. 1) The first point corresponding to the glenoid fossa was marked $10 \mathrm{~mm}$ from the midtragus and $2 \mathrm{~mm}$ below the line, and a second point corresponding to the articular eminence was marked $10 \mathrm{~mm}$ from the first point and 10 $\mathrm{mm}$ below the line. Two $\mathrm{mL}$ of $2 \%$ lignocaine was injected to anesthetize the articular branch of the auriculotemporal nerve. Patients were asked to open their mouth wide and the mandible was held in the protruded position. A 19-gauge needle was then introduced at the first point, and $2 \mathrm{~mL}$ of Ringer lactate was injected through this needle to distend the joint space. Another 19-gauge needle was then inserted at the second point to establish a free flow of the solution through the joint space.(Fig. 2) A syringe filled with Ringer's lactate was injected under pressure into the superior joint space through the first needle; the second needle provided the outflow for the Ringer's lactate. A total of $100 \mathrm{~mL}$ solution was used to lavage the superior joint space and the needles were removed. The patient's lower jaw was gently manipulated in the vertical, protrusive, and lateral excursions to free up the disc. Non-steroidal anti-inflammatory agents and muscle relaxants were advised for 1 week postoperative. Preoperative

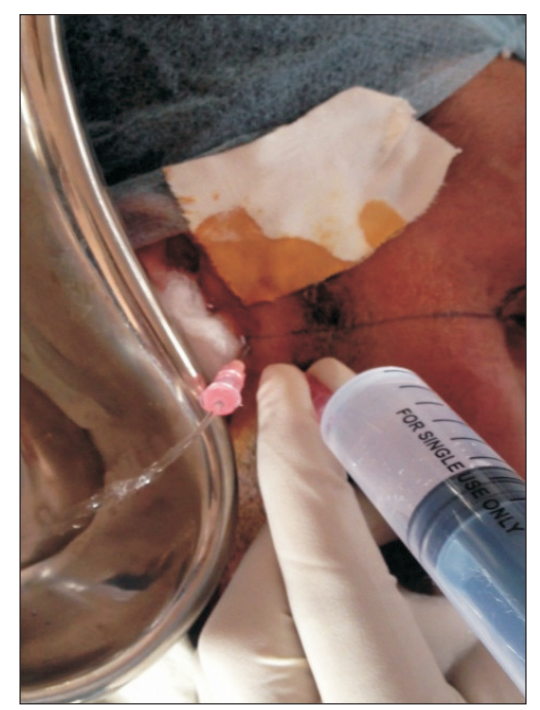

Fig. 2. Arthrocentesis in progresis.

Syed Wakeel Andrabi et al: Clinical factors affecting the outcome of arthocentesis. $J$ Korean Assoc Oral Maxillofac Surg 2019 
and postoperative clinical assessments were performed by a single clinician for signs and symptoms of TMJ disorders which included pain, mouth opening, joint noises, and jaw deviation. Pain was assessed using a visual analogue scale (VAS; 0-10). Mouth opening was measured as the maximum interincisal distance in millimeters. The patients were assessed for all the parameters preoperatively, and postoperatively on day 1, 1 week, 1 month, 3 months, and 6 months. All results are reported as mean and standard deviation, and a $P$-value $<0.05$ was considered significant (SPSS 15; SPSS Inc., Chicago, IL, USA).

\section{Results}

Patient age ranged from 18 to 60 years $(n=50)$. Mean patient age was $28.96 \pm 11.034$ years, and 36 patients were female. Mean preoperative pain VAS score was $6.49 \pm 1.560$. There was statistically significant improvement at every follow-up. At the 6-month follow-up after arthrocentesis, the mean pain VAS score was $0.46 \pm 1.147$ (a mean difference of 6.03 from the preoperative VAS score).(Table 1) There was significant improvement in pain in both males and females and in all age groups. The age group $\leq 25$ years showed the highest preoperative pain score among all groups and the lowest postoperative pain score.(Table 2)

Table 1. Comparison of pain score at different time intervals

\begin{tabular}{lcccccc}
\hline Time interval & Mean & SD & $\begin{array}{c}P \text {-value } \\
\text { (ANOVA) }\end{array}$ & $\begin{array}{c}\text { Compa- } \\
\text { rison }\end{array}$ & $\begin{array}{l}\text { Mean } \\
\text { diffe- } \\
\text { rence }\end{array}$ & $P$-value \\
\hline Preoperative (1) & 6.49 & 1.560 & & - & - & - \\
1 Week (2) & 2.52 & 0.953 & & 1 vs 2 & 3.97 & $<0.001^{*}$ \\
1 Month (3) & 1.44 & 1.053 & $<0.001^{*}$ & 1 vs 3 & 5.05 & $<0.001^{*}$ \\
3 Months (4) & 0.64 & 1.083 & & 1 vs 4 & 5.85 & $<0.001^{*}$ \\
6 Months (5) & 0.46 & 1.147 & & 1 vs 5 & 6.03 & $<0.001^{*}$ \\
\hline
\end{tabular}

(SD: standard deviation)

$* P<0.05$.

Syed Wakeel Andrabi et al: Clinical factors affecting the outcome of arthocentesis. $J$ Korean Assoc Oral Maxillofac Surg 2019

Table 2. Comparison of preoperative pain and pain at 6 months in various age groups

\begin{tabular}{llllllll}
\hline & \multicolumn{2}{c}{$\begin{array}{c}\text { Preoperative } \\
\text { pain }\end{array}$} & & \multicolumn{2}{c}{$\begin{array}{c}\text { Pain after } \\
6 \text { months }\end{array}$} & \multirow{2}{*}{$P$-value } \\
\cline { 2 - 3 } \cline { 5 - 6 } Age group $(y r)$ & Mean & SD & & Mean & SD & \\
\hline$\leq 25$ & 6.92 & 1.283 & & 0.28 & 1.114 & $<0.001^{*}$ \\
$>25$ and $\leq 40$ & 5.89 & 1.833 & & 0.56 & 1.130 & $<0.001^{*}$ \\
$>40$ and $\leq 60$ & 5.56 & 1.74 & & 1.00 & 1.225 & $<0.001^{*}$ \\
\hline
\end{tabular}

(SD: standard deviation)

$* P<0.05$.

Syed Wakeel Andrabi et al: Clinical factors affecting the outcome of arthocentesis. $J$ Korean Assoc Oral Maxillofac Surg 2019
The mean preoperative maximum vertical opening (MVO) was $26.14 \pm 4.969 \mathrm{~mm}$. Twenty-three patients had preoperative MVO $<25 \mathrm{~mm}$ and 27 patients had $>25 \mathrm{~mm}$. There was statistically significant improvement in MVO at every followup. At the 6-month follow-up after arthrocentesis, the mean maximum mouth opening was $38.92 \pm 3.392 \mathrm{~mm}$ with a mean difference of $12.78 \mathrm{~mm}$ from preoperative MVO.(Table 3)

A multiple logistic regression analysis of pretreatment data was used for the simultaneous assessment of each potential clinical variable (age, sex, time since onset [TSO] $\leq 24$ and $>24$ weeks, VAS pain level, and MVO). Age, VAS pain level, and MVO data were categorized and transformed into polychotomous test items prior to carrying out the regression analysis. The categories included were: age $(<25$ years, $>25$ and $\leq 40$ years, $>40$ and $\leq 60$ years), VAS pain level $(\leq 5,>5$

Table 3. Comparison of MVO (mm) at different time intervals

\begin{tabular}{lccccccc}
\hline Time interval & Mean & SD & $\begin{array}{c}P \text {-value } \\
\text { (ANO- } \\
\text { VA) }\end{array}$ & $\begin{array}{c}\text { Com- } \\
\text { parison }\end{array}$ & $\begin{array}{c}\text { Mean } \\
\text { diffe- } \\
\text { rence }\end{array}$ & $P$-value \\
\hline Preoperative (1) & 26.14 & 4.969 & & - & - & - \\
1 Week (2) & 35.32 & 3.235 & & 1 vs 2 & -9.18 & $<0.001^{*}$ \\
1 Month (3) & 36.46 & 3.085 & $<0.001^{*}$ & 1 vs 3 & -10.32 & $<0.001^{*}$ \\
3 Months (4) & 37.68 & 3.377 & & 1 vs 4 & -11.54 & $<0.001^{*}$ \\
6 Months (5) & 38.92 & 3.392 & & 1 vs 5 & -12.78 & $<0.001^{*}$ \\
\hline
\end{tabular}

(MVO: maximum vertical opening, SD: standard deviation) $* P<0.05$.

Syed Wakeel Andrabi et al: Clinical factors affecting the outcome of arthocentesis. $J$ Korean Assoc Oral Maxillofac Surg 2019

Table 4. Comparison of factors between successful and unsuccessful arthrocentesis of the temporomandibular joint outcomes

\begin{tabular}{llrrr}
\hline & & $\begin{array}{c}\text { Successful } \\
\text { outcome } \\
(\mathrm{n}=42)\end{array}$ & $\begin{array}{c}\text { Nonsuccessful } \\
\text { outcome } \\
(\mathrm{n}=8)\end{array}$ & $P$-value \\
\hline Age $(\mathrm{yr})$ & $\leq 25$ & $30(71.4)$ & $2(25.0)$ & $<0.001^{*}$ \\
& $>25$ and $\leq 40$ & $7(16.7)$ & $2(25.0)$ & \\
& $>40$ and $\leq 60$ & $5(11.9)$ & $4(50.0)$ & \\
Sex & Mean \pm SD & $26.6 \pm 9.35$ & $41.3 \pm 11.61$ & \\
& Male & $11(26.2)$ & $3(37.5)$ & 0.823 \\
TSO $(\mathrm{mo})$ & Female & $31(73.8)$ & $5(62.5)$ & \\
& $\leq 24$ & $29(69.0)$ & $3(37.5)$ & 0.112 \\
& $>24$ & $13(31.0)$ & $5(62.5)$ & \\
VAS & Mean \pm SD & $20.3 \pm 8.05$ & $25.0 \pm 3.89$ & \\
& $\leq 5$ & $8(19.0)$ & $5(62.5)$ & $0.006^{*}$ \\
& $>5$ and $\leq 7$ & $16(38.1)$ & $2(25.0)$ & \\
& $>7$ and $\leq 10$ & $18(42.9)$ & $1(12.5)$ & \\
MVO (mm) & Mean \pm SD & $6.8 \pm 1.45$ & $5.1 \pm 1.46$ & \\
& $<25$ & $22(52.4)$ & $1(12.5)$ & 0.362 \\
& $\geq 25$ & $20(47.6)$ & $7(87.5)$ & \\
& Mean \pm SD & $25.9 \pm 5.32$ & $27.6 \pm 2.00$ & \\
\hline
\end{tabular}

(SD: standard deviation, TSO: time since onset, VAS: visual analogue scale, MVO: maximum vertical opening) $* P<0.05$.

Values are presented as number $(\%)$ or mean \pm SD.

Syed Wakeel Andrabi et al: Clinical factors affecting the outcome of arthocentesis. $J$ Korean Assoc Oral Maxillofac Surg 2019 
Table 5. Relative odds of successful treatment outcome as a function of clinical parameters

\begin{tabular}{llcccll}
\hline & & Estimate & Standard error & Odds ratio & 95\% CI & $P$-value \\
\hline Sex & & -0.525 & 0.810 & 0.59 & $0.12-2.89$ & 0.517 \\
Age & $\leq 25$ & 2.485 & 0.992 & 12.01 & $1.72-83.80$ & $0.012 *$ \\
& $>25$ and $\leq 40$ & 1.030 & 1.045 & 2.80 & $0.36-21.73$ & 0.325 \\
TSO & $<24$ & -1.313 & 0.803 & 0.27 & $0.06-1.29$ & 0.102 \\
VAS & $>5$ and $\geq 7$ & 1.609 & 0.942 & 5.01 & $0.79-31.68$ & 0.088 \\
& $>7$ and $\leq 10$ & 2.420 & 1.175 & 11.25 & $1.13-112.54$ & $0.039^{*}$ \\
MVO & $<25$ & 2.041 & 1.113 & 7.70 & $0.87-68.19$ & $0.038^{*}$ \\
\hline
\end{tabular}

(CI: confidence interval, TSO: time since onset, VAS: visual analogue scale, MVO: maximum vertical opening)

$* P<0.05$.

Syed Wakeel Andrabi et al: Clinical factors affecting the outcome of arthocentesis. J Korean Assoc Oral Maxillofac Surg 2019

and $\leq 7,>7$ and $\leq 10)$, and $\mathrm{MVO}(<25$ and $\geq 25 \mathrm{~mm})$.

Odds ratios (ORs) were used to describe the proportional benefit that an individual with a given clinical feature would belong to the successful treatment group. For the OR to be clinically relevant or even clinically noticeable, we assumed it would need to be larger than 2 . There was a significant difference between categories by age $(P=0.0019)$ and VAS pain level $(P=0.006)$. (Table 4$)$

Logistic regression analysis showed a significant increase in successful outcomes for the age group $<25$ years (OR, 12.01; $P=0.012$ ), a VAS pain level of $>7$ (OR, 11.25; $P=0.039$ ), and a MVO of $<25 \mathrm{~mm}(\mathrm{OR}, 7.70 ; P=0.038)$.(Table 5)

\section{Discussion}

There is clinical evidence supporting the existence of disc displacement in TMJ internal derangement. However, the current consensus suggests that a change in the position of the disc is not a primary factor in TMJ pain and dysfunction. However, alterations in joint pressure (negative intra-articular pressure), a variety of biochemical substances, and constituents of the synovial fluid (and thereby failure of lubrication) may lead to clicking and TMJ derangement ${ }^{2,6,7}$.

Lavage of the upper joint space reduces joint pain by removing inflammatory mediators, increasing mandibular mobility by removing intra-articular adhesions, eliminating the negative pressure within the joint, recovering disc and fossa space, and improving disc mobility, which reduces the mechanical obstruction caused by the anterior position of disc ${ }^{8-12}$. Arthrocentesis under sufficient pressure can also remove adhesions, widen the joint spaces, and improve mouth opening ${ }^{12,13}$.

Mean preoperative pain VAS score was $6.49 \pm 1.560$, and mean preoperative MVO was $26.14 \pm 4.969 \mathrm{~mm}$. There was statistically significant improvement at every follow-up. At the 6-month postoperative follow-up after arthrocente- sis, the mean pain VAS scale was $0.46 \pm 1.147$ with a mean difference of 6.03 from the preoperative value. The MVO was $38.92 \pm 3.392 \mathrm{~mm}$ with a mean difference of $12.78 \mathrm{~mm}$ from preoperative opening value. The overall success rate at 6-month follow-up was $84 \%$, which is in accord with studies by Carvajal and Laskin (88\%), but their study follow-up was from 10 to 96 months $^{1,14}$.

The success rate of arthrocentesis in our study was $84 \%$; the rest of the cases were classified as unsuccessful because of persistent pain and decreased mouth opening. The results of the present study showed patient age in the unsuccessful outcome group was significantly higher than that in the successful outcome group. This observation is consistent with other studies, which showed mean patient age in failed instances was older than that in successful outcomes ${ }^{15-17}$.

The consistent age difference in successful outcomes may be attributed to biologically based differences in TMJ status.

Patients with a successful outcome had a higher VAS pain level and a more restricted ROM than those with an unsuccessful outcome ${ }^{13}$. One hypothesis is that in these instances pronounced inflammatory processes associated with alterations in the constituents of the synovial fluid were the main underlying mechanisms. Pain and maximum mouth opening and dysfunction are interrelated. More pain results in severe reduction in mouth opening.

The present study also evaluated the contribution of age, TSO, VAS pain level, and MVO to TMJ arthrocentesis outcomes. Age $<25$ years, VAS pain level $>7$, and MVO $<25$ $\mathrm{mm}$ significantly contributed to the change in arthrocentesis prognosis which is in accord with the study by Emshoff ${ }^{13}$. Although these features may not be considered the unique and dominant factors in the definition of arthrocentesis outcome groups, the contribution of these variables was not 0 , and the elevation in the ORs indicates that they are probably contributing biologically. Further investigations are necessary to determine the extent these factors and additional morpho- 
logical and psychological features contribute. In the present study age, VAS pain level, and MVO were associated with TMJ pain and MVO. Arthroscopic studies have provided evidence that inflammatory processes in the synovium, capsule, or retrodiscal tissues are the underlying mechanisms for TMJ pain $^{15-19}$. Therapeutic procedures including arthrocentesis were described to correct the dysfunctional state by washing away inflammatory products, lubricating joint surfaces, and promoting healthy synovial fluid production ${ }^{1,8}$.

Arthrocentesis is more effective in TMJ disorders with pronounced inflammatory components, and those with a less pronounced inflammatory component affect arthrocentesis outcomes $^{7,20}$.

The findings of the present study support that the prediction of a specific outcome is not a matter of simple linearity, but rather is a function of a complex interaction among different variables. Therefore, efforts to predict which patients are most likely to benefit from specific treatment approaches have important clinical prevention and treatment implications.

Transient swelling of the neighboring tissues due to perfusion of Ringer's solution into the surrounding tissues may occur during arthrocentesis. In our study, immediate postoperative swelling was encountered in a majority of patients, but the swelling subsided overnight in all the cases. Transient temporal branch palsy resulting in the inability to close the upper eyelid also occurred in some cases but was selflimiting ${ }^{18,20}$. Otherwise there were no serious postoperative complications. Arthrocentesis prognosis may be diverse and complex due to different the prognostic factors involved; however, arthrocentesis improves disc displacement. Since arthrocentesis is simple, the procedure can be repeated ${ }^{21}$.

\section{Conclusion}

Arthrocentesis a simple and intermediate procedure between medical and open surgical treatment. Arthrocentesis is minimally invasive with less intraoperative and postoperative complications. Lavage of the superior joint space with Ringer's lactate results in significant reduction in pain and improvement in mouth opening. Preoperative evaluation of clinical variables may help in identifying patients likely to benefit from arthrocentesis.

\section{ORCID}

Syed Wakeel Ahmad, https://orcid.org/0000-0002-59891325

Altaf H. Malik, https://orcid.org/0000-0002-7420-0035

Ajaz A. Shah, https://orcid.org/0000-0001-7224-6497

\section{Authors' Contributions}

S.W.A. paticipated in the data collection and stastiscial analysis. A.H.M. wrote the manuscript and carried the operative part of study and helped in study design. A.A.S. helped in drafting the manuscript and helped in study design.

\section{Ethics Approval and Consent to Participate}

This study was approved by the chairman of Department of Oral and Maxillofacial Surgery, Government Dental College, Srinagar, India (approval no. 2012-omfs-GDC Srinagar-1), and the written informed consents were obtained from all patients.

\section{Consent for Publishing Photographs}

Written informed consent was obtained from the patients for publication of this article and accompanying images.

\section{Conflict of Interest}

No potential conflict of interest relevant to this article was reported.

\section{References}

1. Carvajal WA, Laskin DM. Long-term evaluation of arthrocentesis for the treatment of internal derangements of the temporomandibular joint. J Oral Maxillofac Surg 2000;58:852-5; discussion 856-7.

2. Dolwick MF. Intra-articular disc displacement. Part I: its questionable role in temporomandibular joint pathology. J Oral Maxillofac Surg 1995;53:1069-72.

3. Frost DE, Kendell BD. Part II: the use of arthrocentesis for treatment of temporomandibular joint disorders. J Oral Maxillofac Surg 1999;57:583-7.

4. Truelove EL, Sommers EE, LeResche L, Dworkin SF, Von Korff M. Clinical diagnostic criteria for TMD. New classification permits multiple diagnoses. J Am Dent Assoc 1992;123:47-54.

5. McCain JP, Hossameldin RH. Arthroscopic arthroplasty of the temporomandibular joint. In: Haggerty CJ, Laughlin RM, eds. Atlas of operative oral and maxillofacial surgery. Ames: Wiley Blackwell; 2015:271-80.

6. Alpaslan C, Bilgihan A, Alpaslan GH, Güner B, Ozgür Yis M, Erbaş D. Effect of arthrocentesis and sodium hyaluronate injection 
on nitrite, nitrate, and thiobarbituric acid-reactive substance levels in the synovial fluid. Oral Surg Oral Med Oral Pathol Oral Radiol Endod 2000;89:686-90.

7. Nishimura M, Segami N, Kaneyama K, Sato J, Fujimura K. Comparison of cytokine level in synovial fluid between successful and unsuccessful cases in arthrocentesis of the temporomandibular joint. J Oral Maxillofac Surg 2004;62:284-7; discussion 287-8.

8. Nitzan DW, Dolwick MF, Martinez GA. Temporomandibular joint arthrocentesis: a simplified treatment for severe, limited mouth opening. J Oral Maxillofac Surg 1991;49:1163-7; discussion 116870.

9. Kaneyama K, Segami N, Nishimura M, Sato J, Fujimura K, Yoshimura $\mathrm{H}$. The ideal lavage volume for removing bradykinin, interleukin-6, and protein from the temporomandibular joint by arthrocentesis. J Oral Maxillofac Surg 2004;62:657-61.

10. Moses JJ, Sartoris D, Glass R, Tanaka T, Poker I. The effect of arthroscopic surgical lysis and lavage of the superior joint space on TMJ disc position and mobility. J Oral Maxillofac Surg 1989;47:674-8.

11. Dimitroulis G, Dolwick MF, Martinez A. Temporomandibular joint arthrocentesis and lavage for the treatment of closed lock: a followup study. Br J Oral Maxillofac Surg 1995;33:23-6; discussion 26-7.

12. Yura S, Totsuka Y, Yoshikawa T, Inoue N. Can arthrocentesis release intracapsular adhesions? Arthroscopic findings before and after irrigation under sufficient hydraulic pressure. J Oral Maxillofac Surg 2003;61:1253-6.

13. Emshoff R. Clinical factors affecting the outcome of arthrocentesis and hydraulic distension of the temporomandibular joint. Oral Surg Oral Med Oral Pathol Oral Radiol Endod 2005;100:409-14.

14. Murakami K, Hosaka H, Moriya Y, Segami N, Iizuka T. Short-term treatment outcome study for the management of temporomandibular joint closed lock. A comparison of arthrocentesis to nonsurgical therapy and arthroscopic lysis and lavage. Oral Surg Oral Med Oral Pathol Oral Radiol Endod 1995;80:253-7.

15. Nishimura M, Segami N, Kaneyama K, Suzuki T. Prognostic factors in arthrocentesis of the temporomandibular joint: evaluation of 100 patients with internal derangement. J Oral Maxillofac Surg 2001;59:874-7; discussion 878 .

16. Israel HA, Diamond B, Saed-Nejad F, Ratcliffe A. Osteoarthritis and synovitis as major pathoses of the temporomandibular joint: comparison of clinical diagnosis with arthroscopic morphology. J Oral Maxillofac Surg 1998;56:1023-7; discussion 1028.

17. Israel HA, Saed-Nejad F, Ratcliffe A. Early diagnosis of osteoarthrosis of the temporomandibular joint: correlation between arthroscopic diagnosis and keratan sulfate levels in the synovial fluid. J Oral Maxillofac Surg 1991;49:708-11; discussion 712.

18. Murakami K, Segami N, Fujimura K, Iizuka T. Correlation between pain and synovitis in patients with internal derangement of the temporomandibular joint. J Oral Maxillofac Surg 1991;49:1159-61; discussion 1162.

19. Sakamoto I, Yoda T, Tsukahara H, Imai H, Enomoto S. Comparison of the effectiveness of arthrocentesis in acute and chronic closed lock: analysis of clinical and arthroscopic findings. Cranio 2000;18:264-71.

20. Monje-Gil F, Nitzan D, González-Garcia R. Temporomandibular joint arthrocentesis. Review of the literature. Med Oral Patol Oral Cir Bucal 2012;17:e575-81.

21. Kim YH, Jeong TM, Pang KM, Song SI. Influencing factor on the prognosis of arthrocentesis. J Korean Assoc Oral Maxillofac Surg 2014;40:155-9. 